\title{
BMJ Open Depression among adult patients with primary brain tumour: a cross-sectional study of risk factors in a low-middle- income country
}

\author{
Anum Sadruddin Pidani (D) , ${ }^{1}$ Amna Rehana Siddiqui, ${ }^{1}$ Iqbal Azam, ${ }^{1}$ \\ Muhammad Shahzad shamim, ${ }^{2}$ Adnan Abdul Jabbar, ${ }^{3}$ Shameel Khan ${ }^{4}$
}

To cite: Pidani AS, Siddiqui AR, Azam I, et al. Depression among adult patients with primary brain tumour: a cross-sectional study of risk factors in a low-middleincome country. BMJ Open 2020;10:e032748. doi:10.1136/ bmjopen-2019-032748

- Prepublication history for this paper is available online. To view these files, please visit the journal online (http://dx.doi org/10.1136/bmjopen-2019032748).

Received 05 July 2019 Revised 04 June 2020 Accepted 21 July 2020

D) Check for updates

(c) Author(s) (or their employer(s)) 2020. Re-use permitted under CC BY-NC. No commercial re-use. See rights and permissions. Published by BMJ.

${ }^{1}$ Community Health Sciences, Aga Khan University, Karachi, Pakistan

${ }^{2}$ Surgery, Aga Khan University, Karachi, Pakistan

${ }^{3}$ Oncology, Aga Khan University Medical College Pakistan, Karachi, Sindh, Pakistan

${ }^{4}$ Psychiatry, Aga Khan University, Karachi, Pakistan

Correspondence to Dr Muhammad Shahzad shamim;

shahzad.shamim@aku.edu

\section{ABSTRACT}

Objective The prevalence of depression among patients with primary brain tumour ranges from $15 \%$ to $40 \%$ globally. Several individual and clinical factors contribute to the development of depression. However, their association with depression in Pakistani setting has not yet been assessed. Thus, we aim to study the factors associated with depression among adult patients with primary brain tumour at a tertiary care hospital in Karachi, Pakistan.

Study design A prospective cross-sectional study. Setting This study was conducted at a tertiary care hospital of Karachi, Pakistan.

Participants This study included 132 patients with confirmed diagnosis of primary brain tumour (initially diagnosed on MRI of the brain with contrast and later confirmed on histology of surgical specimen) in various stages of treatment.

Primary outcome The primary outcome of this study was to assess depression and its associated factors among adult patients with primary brain tumour. Depression was assessed using a validated screening tool Patient Health Questionnaire-9 (PHQ-9). Scores of 10-27 on PHQ-9 were indicative of screen positive for depressive symptoms. A set of the structured pre-tested questions was used to evaluate patient-related, tumor-related and treatmentrelated factors.

Results Fifty-one (39\%, Cl: 33.33-46.94) patients in our study screened positive for depressive symptoms on PHQ-9. There was a significant association between depressive symptoms and Karnofsky Performance Scores (KPS) (prevalence ratio: 3.25 and Cl: 1.87-5.62) after controlling covariates. Propensity scores predicted a positive association between KPS (functional status) and unemployment, treatment stage, and tumour recurrence. Tumor-related and treatment-related factors including tumour grade, location, type and hemispheric lateralisation were found insignificant.

Conclusion Depression is common in patients with primary brain tumour. Impaired functional status has a direct impact on depression in these patients. Incorporating the psychosocial domain earlier in the course of treatment needs to be considered for better neuro-oncology management of patients with primary brain tumour.
Strengths and limitations of this study

- To our knowledge, this was the first study conducted in Pakistan to explore depression and its associated factors among patients with primary brain tumour.

- The study has assessed those associations which were not assessed in any of the previous studies on a similar population including treatment stage, extra ventricular drain insertion, number of admissions, stressful events, strategies use to handle stress and first symptoms. Moreover, the relation of different costs including travelling cost and overall treatment cost with depression was also evaluated in this study.

- A single screening tool to measure depression instead of physician-rated measures or miniinterviews was used to verify the results of Patient Health Questionnaire-9.

- The study design is cross-sectional which limits both temporality and direction of causation.

\section{BACKGROUND}

Although primary brain tumours account for a relatively small percentage of all cancers, it is considered one of the most devastating types of cancers among the adult population. ${ }^{1}$ The incidence of primary brain tumours is approximately $9 / 100000 /$ year worldwide with higher rates in western countries as compared with low-middle-income countries (LMICs). ${ }^{2}$ Interestingly, primary brain tumours rank highest among cancers that cause an emotional and psychological burden for patients. ${ }^{34}$

Diagnostic and Statistical Manual-V defines depression as a feeling of sadness, loss of pleasure from daily living activities, body weight changes, reduction in physical activity, fatigue, failure to think or concentrate, lack of self-worth and recurrent suicidal ideations. ${ }^{5}$ It is estimated that depression affects about 350 million individuals worldwide and according to the Global Mental 
Health Survey (2014), nearly 1 in 20 individuals report having at least one episode of depression within a year. ${ }^{6}$ Population-based researches report a prevalence of clinical depression ranging between $2 \%$ and $5 \%$ worldwide. ${ }^{7}$ The worldwide prevalence of depression in patients with cancer is $25 \%$ with higher rates among Asian countries. ${ }^{8}$ The estimated prevalence of clinically diagnosed depression in Pakistan is approximately $6 \%$ out of which $3 \%$ are patients with cancer. ${ }^{9}$ Depression rates among patients with primary brain tumour range from $15 \%$ to $40 \%$ with the highest rates among patients with glioma. ${ }^{10}$ However, it is suggested that these rates likely under-represent the true incidence of depression. ${ }^{11} \mathrm{~A}$ systematic review of 42 observational studies reports that the prevalence of depression among patients with glioma ranges between $0 \%$ and $93 \%$ with a median prevalence of $27 \% .^{12}$

Depression in patients with brain tumour is multifactorial and there are several factors contributing to its development, including individual, tumor-related and disease-related factors. ${ }^{10}$ All the studies on this topic to date have been conducted in the western population, where the psychosocial circumstances are much different from the Pakistani population, for example, in the UK and US, where most of the data come from, the majority of patients are financially supported by third party payers, that is, state or insurance. In contrast, approximately 85\% of patients in Pakistan and a few other South Asian LMICs are out-of-pocket payers both for their treatment and rehabilitation. ${ }^{13}$ This, we believe, may be the cause of the additional psychological burden on the patients. This and several other factors like social support, family set-up and social status are unknown in the context of settings of LMICs and require a series of researches to establish associations. The aim of this study was to assess the association between depression and patient-related, tumor-related and treatment-related variables among adult patients with primary brain tumour in an LMIC.

\section{METHODS}

\section{Study design}

The analytical cross-sectional study design was employed to determine the association between patient-related, tumor-related and treatment-related factors with depression among adult patients with primary brain tumour. Non-probability consecutive sampling was used to recruit subjects. All the patients who met the eligibility criteria of the study and were willing to give consent were included in the study.

\section{Site and setting}

The recruitment was conducted at tertiary care setting of Karachi, Pakistan and 132 patients with confirmed diagnosis of primary brain tumours at various stages of treatment were enrolled. These patients were contacted in neurosurgery wards, neurosurgery and oncology outpatient clinics, and oncology day care suits from November 2017 to July 2018.

\section{Participants}

Participants were all adult patients (aged 18 years and above) with a confirmed diagnosis of primary brain tumour (initially diagnosed on MRI of the brain with contrast and later confirmed on histology of surgical specimen) in various stages of treatment at a tertiary care set-up. Each patient was enrolled after written, informed consent. The exclusion criteria for study participants were as follows: diagnosis of depression for about 1 year prior to the diagnosis of primary brain tumour, confused or incoherent patients and patients having problems with speech or comprehension that prevents them from completing the questionnaire, patients with coexisting systemic malignancies apart from a primary brain tumour and any severe comorbid medical illness such as liver cirrhosis, systemic infections like HIV and hepatitis which can cause altered mental status.

\section{Procedure}

Participants' eligibility was determined by medical record files. Potentially eligible participants were approached by the investigator during a scheduled follow-up visit at neurosurgery and oncology outpatient clinics and inpatient hospital stay post-surgery. Each patient after the consent was interviewed for $15-20 \mathrm{~min}$ to fill a structured pre-tested questionnaire ${ }^{14}$ for assessing predictor variables and Patient Health Questionnaire-9 (PHQ-9) Scale for the screening of depression. The questionnaire was also pilot tested on 10 participants before the actual administration.

\section{Measures}

We divided all the associated factors into three distinct categories that were patient-related, tumor-related and treatment-related variables. Patient-related factors comprised of demographic and socioeconomic variables including age, gender, marital status, number of dependents, children under 18 years, education, occupation, employment status, residency, travelling cost, caregiver support, current smoking status, past/current medical illness, history of psychological distress, strategies to handle stress (isolation, aggression, prayers, crying, sleeping, addiction and mind diversions) and functional status. The participant's functional status was assessed using the Karnofsky Performance Score (KPS). KPS scores less than 70 were indicative of impaired functional status. Socio-economic status was also computed using factorial analysis. Tumor-related and treatment-related variables were assessed by medical record review and included tumour histology, tumour grade, recurrence, hemispheric lateralisation, first symptoms, brain structures involved and cognitive impairment. Treatmentrelated variables included stage of treatment, number of chemotherapy cycles, duration since diagnosed, radiation therapy, current use of steroids and anti-epileptic drugs, and treatment cost. The complete list of variables is mentioned in table 1 . 
Table 1 Summary of the descriptive characteristics of study participants

\begin{tabular}{|c|c|c|c|}
\hline \multirow[b]{2}{*}{ S\# } & \multirow[b]{2}{*}{ Variables } & \multirow{2}{*}{$\begin{array}{l}\text { Total } \\
\mathbf{N}(\%)\end{array}$} & \multirow{2}{*}{$\begin{array}{l}\text { Screened positive for } \\
\text { depressive symptoms (PHQ-9 } \\
\geq 10 \text { ) } \\
\mathrm{N}(\%)\end{array}$} \\
\hline & & & \\
\hline \multicolumn{4}{|c|}{ Patient-related variables } \\
\hline \multirow[t]{3}{*}{1} & Marital status & & \\
\hline & Married & $117(89)$ & $43(37)$ \\
\hline & Unmarried/single/separated/divorced & $15(11)$ & $8(53)$ \\
\hline \multirow[t]{4}{*}{2} & Children under 18 years & & \\
\hline & Yes & $75(57)$ & $32(43)$ \\
\hline & No & $33(25)$ & $10(30)$ \\
\hline & Unmarried & $24(18)$ & $9(38)$ \\
\hline \multirow[t]{4}{*}{3} & Current employment status & & \\
\hline & Able to work & $65(49)$ & $18(28)$ \\
\hline & Unable to work & $24(18)$ & $13(54)$ \\
\hline & Unpaid (retired/student/housewives) & $43(33)$ & $20(47)$ \\
\hline \multirow[t]{3}{*}{4} & Residence & & \\
\hline & In Karachi & $49(37)$ & $19(39)$ \\
\hline & Outside Karachi & $83(63)$ & $32(39)$ \\
\hline \multirow[t]{5}{*}{5} & Travel cost for one visit (from home & hospital) & \\
\hline & 5000-10 000 Rupees & $26(20)$ & $5(19)$ \\
\hline & 11000-20 000 Rupees & $39(30)$ & $18(46)$ \\
\hline & >20000 Rupees & $18(13)$ & $9(50)$ \\
\hline & Not applicable & $49(37)$ & $19(39)$ \\
\hline \multirow[t]{4}{*}{6} & Caregiver at home & & \\
\hline & Spouse & $92(70)$ & $33(36)$ \\
\hline & Parents & $14(10)$ & $08(57)$ \\
\hline & Others (kids/neighbours/siblings/self) & $26(20)$ & $10(38)$ \\
\hline \multirow[t]{3}{*}{7} & Heading family & & \\
\hline & Yes & $68(52)$ & $27(40)$ \\
\hline & No & $64(48)$ & $24(38)$ \\
\hline \multirow[t]{4}{*}{8} & Socioeconomic status (SES) & & \\
\hline & Low SES & $22(17)$ & $9(41)$ \\
\hline & Middle SES & $83(63)$ & $32(39)$ \\
\hline & High SES & $27(20)$ & $10(37)$ \\
\hline \multirow[t]{3}{*}{9} & Currently smoking (cigarette, huqa, & & \\
\hline & Yes & $18(14)$ & $10(56)$ \\
\hline & No & $114(86)$ & $41(36)$ \\
\hline \multirow[t]{3}{*}{10} & History of psychological distress pr & 1e diagnosi & \\
\hline & Yes & $7(5)$ & $6(86)$ \\
\hline & No & $125(95)$ & $45(36)$ \\
\hline
\end{tabular}


Screened positive for depressive symptoms (PHQ-9 $\geq 10$ )

\begin{tabular}{llll} 
& & Total & $\geq \mathbf{1 0})$ \\
$\mathbf{S} \#$ & Variables & $\mathbf{N}(\%)$ & $\mathbf{N}(\%)$ \\
\hline 11 & Strategies to handle stress & $26(20)$ & $10(38)$ \\
& Isolation & $16(12)$ & $7(44)$ \\
& Crying & $48(36)$ & $14(29)$ \\
& Prayers & $24(18)$ & $13(54)$ \\
& Aggression & $1(0.7)$ & $1(1.96)$ \\
& Leaves home & $13(9)$ & $6(45)$ \\
& Sleeping & $10(7)$ & $1(10)$ \\
& Conversation with family/friends & $6(4)$ & $4(66)$ \\
& Addictions (smoking/drinking) & $2(1)$ & $0(0)$ \\
& Mind diversions (listening to music/shopping) & \\
Karnofsky Performance Score (KPS) (functional status) & $102(77)$ & $27(26)$ \\
& KPS scores $>70$ & $30(23)$ & $24(80)$
\end{tabular}

\section{Treatment-related variables}

\begin{tabular}{|c|c|c|c|}
\hline \multirow[t]{4}{*}{13} & \multicolumn{3}{|l|}{ Overall treatment cost during illness } \\
\hline & 200000-800000 Rupees & $45(34)$ & $17(38)$ \\
\hline & $800000-1200000$ Rupees & $47(36)$ & $20(43)$ \\
\hline & >1200000 Rupees & $40(30)$ & $14(35)$ \\
\hline \multirow[t]{5}{*}{14} & \multicolumn{3}{|l|}{ Treatment cost management } \\
\hline & Self-support & $73(55)$ & $25(34)$ \\
\hline & Family/relative support & $21(16)$ & $11(52)$ \\
\hline & Welfare from primary treating hospital & $28(21)$ & $13(46)$ \\
\hline & Medical support from workplace/community & $10(8)$ & $2(20)$ \\
\hline \multirow[t]{3}{*}{15} & \multicolumn{3}{|l|}{ Access to health insurance } \\
\hline & Yes & $15(11)$ & $3(20)$ \\
\hline & No & $117(89)$ & $48(41)$ \\
\hline \multirow[t]{5}{*}{16} & \multicolumn{3}{|l|}{ Treatment stage at the time of interview } \\
\hline & Only surgical procedure done & $17(13)$ & $14(82)$ \\
\hline & Referral given to oncology after surgery & $18(13)$ & $5(28)$ \\
\hline & Oncology treatment started/continued & $25(19)$ & $10(40)$ \\
\hline & Treatment completed/follow-ups & $72(55)$ & $22(31)$ \\
\hline \multirow[t]{3}{*}{17} & \multicolumn{3}{|l|}{ Current use of steroids } \\
\hline & Yes & $22(17)$ & $13(59)$ \\
\hline & No & $110(83)$ & $38(35)$ \\
\hline \multirow[t]{3}{*}{18} & \multicolumn{3}{|l|}{ Current use of anti-epileptic drugs } \\
\hline & Yes & $48(36)$ & $17(35)$ \\
\hline & No & $84(64)$ & $34(40)$ \\
\hline \multirow[t]{3}{*}{19} & \multicolumn{3}{|c|}{ Surgical procedure performed to remove tumour } \\
\hline & Craniotomy/craniectomy & $96(73)$ & $41(43)$ \\
\hline & Trans-sphenoidal resection & $36(27)$ & $10(28)$ \\
\hline
\end{tabular}

Continued 


\begin{tabular}{|c|c|c|c|}
\hline \multirow[b]{2}{*}{ S\# } & \multirow[b]{2}{*}{ Variables } & Total & $\begin{array}{l}\text { depressive symptoms (PHQ-9 } \\
\geq 10 \text { ) }\end{array}$ \\
\hline & & $\mathbf{N}(\%)$ & $\mathbf{N}(\%)$ \\
\hline \multirow[t]{3}{*}{20} & Type of surgery & & \\
\hline & Awake (local anaesthesia/scalp block) & $37(28)$ & $12(32)$ \\
\hline & Conventional (general anaesthesia) & $95(72)$ & $39(41)$ \\
\hline \multirow[t]{3}{*}{21} & External ventricular drain insertion & & \\
\hline & Yes & $7(5)$ & $5(71)$ \\
\hline & No & $125(95)$ & $46(37)$ \\
\hline \multirow[t]{2}{*}{22} & Time since diagnosis (in months) & Median: 9.5 & Median: 5 \\
\hline & & Range:(1-74) & Range:(1-74) \\
\hline \multirow[t]{2}{*}{25} & Number of chemotherapy cycles & Median: 2.5 & Median: 0 \\
\hline & & Range: (0-33) & Range:(0-27) \\
\hline \multirow[t]{2}{*}{26} & Number of radiation cycles & Median: 3.5 & Median: 0 \\
\hline & & Range: (0-33) & Range:(0-54) \\
\hline
\end{tabular}

\section{Tumour histology}

Meningioma

Pituitary adenoma

High-grade glioma (astrocytoma, GBM)

Oligodendroglioma

Others (schwannoma, intraventricular

SOLs, CNS lymphoma, ependymoma, hemangioblastoma, craniopharyngioma, choroid plexus papilloma)

\begin{tabular}{|c|c|c|c|}
\hline \multirow[t]{3}{*}{28} & \multicolumn{3}{|l|}{ Tumour type } \\
\hline & Benign & $69(52)$ & $28(41)$ \\
\hline & Malignant & $63(48)$ & $23(37)$ \\
\hline \multirow{2}{*}{29} & Left & $60(45)$ & $28(47)$ \\
\hline & Right & $35(27)$ & $13(37)$ \\
\hline \multirow{4}{*}{30} & Grade I & $12(9)$ & $05(42)$ \\
\hline & Grade II & $30(23)$ & $14(47)$ \\
\hline & Grade III & $30(23)$ & $13(43)$ \\
\hline & Grade IV & $16(12)$ & $7(47)$ \\
\hline 31 & No & $123(93)$ & $46(37)$ \\
\hline \multirow[t]{3}{*}{32} & \multicolumn{3}{|l|}{ Tumour recurrence } \\
\hline & Yes & $23(17)$ & $14(61)$ \\
\hline & No & $109(83)$ & $37(34)$ \\
\hline
\end{tabular}

Continued
16 (53)

$9(25)$

9 (43)

8 (28)

$9(56)$ 
Table 1 Continued

\begin{tabular}{|c|c|c|c|}
\hline \multirow[b]{2}{*}{ S\# } & \multirow[b]{2}{*}{ Variables } & \multirow{2}{*}{$\begin{array}{l}\text { Total } \\
\text { N (\%) }\end{array}$} & \multirow{2}{*}{$\begin{array}{l}\text { depressive symptoms (PHQ-S } \\
\geq 10) \\
\mathrm{N}(\%)\end{array}$} \\
\hline & & & \\
\hline \multirow[t]{10}{*}{33} & \multicolumn{3}{|c|}{ Brain structures involved (tumour location) } \\
\hline & Frontal lobe & $53(40)$ & $23(43)$ \\
\hline & Parietal lobe & $30(22)$ & $13(43)$ \\
\hline & Temporal lobe & $26(19)$ & $10(38)$ \\
\hline & Occipital lobe & $5(3)$ & $1(20)$ \\
\hline & Pituitary gland (seller region) & $36(27)$ & $9(25)$ \\
\hline & Ventricles & $5(4)$ & $3(60)$ \\
\hline & Cerebellum/CP angle & $7(4)$ & $6(85)$ \\
\hline & Posterior fossa & $1(1)$ & $0(0)$ \\
\hline & Basal ganglia & $1(1)$ & $0(0)$ \\
\hline \multirow[t]{17}{*}{34} & \multicolumn{3}{|l|}{$\begin{array}{l}\text { First symptoms before brain tumour } \\
\text { diagnosis }\end{array}$} \\
\hline & Seizures & $40(30)$ & $14(35)$ \\
\hline & Headaches & $55(42)$ & $25(45)$ \\
\hline & Weight loss/gain & $3(2)$ & $1(33)$ \\
\hline & Mood changes/loss of interest & $1(1)$ & $1(100)$ \\
\hline & Visual impairment & $36(27)$ & $10(28)$ \\
\hline & Memory loss & $5(3)$ & $3(60)$ \\
\hline & Gait instability & $1(1)$ & $1(2)$ \\
\hline & Nausea/vomiting & $5(3)$ & $2(40)$ \\
\hline & Unconsciousness & $7(5)$ & $2(29)$ \\
\hline & Dizziness & $1(1)$ & $0(00)$ \\
\hline & $\begin{array}{l}\text { Slurred speech/unable to write and } \\
\text { comprehend }\end{array}$ & $3(2)$ & $1(33)$ \\
\hline & Numbness (arms, legs, body) & $2(1)$ & $1(50)$ \\
\hline & Limb weakness & $2(1)$ & $1(50)$ \\
\hline & Swelling (facial, orbital) & $3(2)$ & $2(67)$ \\
\hline & Sexual dysfunction & $1(1)$ & $0(0)$ \\
\hline & Hearing problems & $1(1)$ & $0(0)$ \\
\hline
\end{tabular}

CNS, central nervous system; CP, cerebellopontine; GBM, glioblastoma multiforme; PHQ-9, Patient Health Questionnaire-9; SOLs, spaceoccupying lesions.

\section{Depression}

Patients with primary brain tumour were screened for depression using the Urdu version (the national language of Pakistan) of PHQ-9. The PHQ-9 is a self-rated screening tool which contains nine items that correspond to DSM-V criteria of depression and rated on Likert Scale of 4 points. All the patients were classified into two groups based on the scores on the PHQ-9 Scale. Participants with a score of $\geq 10$ were classified as screened positive for depression. PHQ-9 score of 10 or above has a sensitivity and specificity of $88 \%$ for major depressive symptoms. A recently conducted validation study on Urdu version of PHQ-9 by Gholizadeh et al, ${ }^{15}$ reported a specificity of $94 \%$ and a false-positive rate of $6 \%$ only.

\section{Statistical analysis}

Sample size was calculated from previous study ${ }^{16}$ using Openepi ${ }^{17}$ with a power of $80 \%$, depression to no depression ratio of $1: 2$, prevalence ratio (PR) of $2 \%$ and $30 \%-70 \%$ range of depression for different factors yield a sample size of 108 . Adding $20 \%$ of the attrition rate, the final sample size came out to be 130 participants. We used Stata V.12.0 $0^{18}$ to perform all the analyses. For descriptive data of continuous variables, mean and SDs were computed. Frequencies and percentages were computed for all qualitative variables. We applied the Cox algorithm to obtain crude and adjusted prevalence ratios. ${ }^{19}$ At the univariate level, independent variables were considered significant if the $\mathrm{p}$ value was $\leq 0.25 .{ }^{20}$ We also checked 
multicollinearity between all the predictor variables. To assess multicollinearity, three different tests were used. Pearson's correlation was used for two normally distributed continuous variables, ETA was used for one qualitative and one quantitative variable; whereas, Cramer's V was used for two qualitative variables. Moreover, the cutoff for multicollinearity was 0.8 . After multicollinearity, multivariable analysis was performed using the Cox algorithm to obtain adjusted PR. The cut-off for the significance of the predictor variable at multivariable analysis was $\leq 0.05$. We also calculated propensity scores for the only significant variable left after performing multivariable model building (functional status). The purpose of computing propensity scores was to identify the factor associated with the functional status and understand the vicious pathway of associations between explanatory variables and depression. To predict propensity scores, functional status was kept as a dependent variable and was regressed with other explanatory variables. After the final model was obtained for functional status, propensity scores were computed. At last, propensity scores were regressed against depression (dependent variable in the study) to see its association with depression. The cut-off for the significance of propensity scores was $\leq 0.05$.

\section{Patient and public involvement}

None of the study participants was involved in the design or conduct of this study and no patient opinion regarding the study has been obtained. The results have been reported to head of mind and brain service line at Aga Khan University Hospital (AKUH) in Karachi which primarily deals with neuro-oncology patients.

\section{RESULTS}

\section{Descriptive characteristics of the study participants}

The mean age $( \pm \mathrm{SD})$ of study participants was 43.25 $( \pm 12.28)$ years, with $86(65 \%)$ men and $46(35 \%)$ women. Fifty-one (39\%) study participants were screened positive (scores of 10 and greater on PHQ-9) for depression while 81 participants $(61 \%)$ were screened negative (scores less than 10 on PHQ-9) for depression. Table 1 shows the descriptive characteristics of study participants.

\section{Univariate analysis}

Univariate analysis showed that impaired functional status $(\mathrm{p}<0.001)$, unemployment $(\mathrm{p}=0.121)$, travel cost $(\mathrm{p}=0.240)$, current smoking status $(\mathrm{p}=0.238)$, history of psychological distress prior to the diagnosis of brain tumour $(\mathrm{p}=0.073)$, prayer (strategies to handle stress) $(\mathrm{p}=0.176)$, aggression (strategies to handle stress) $(\mathrm{p}=0.195)$, health insurance $(\mathrm{p}=0.178)$, treatment stage at the time of interview $(\mathrm{p}=0.041)$, current use of steroids $(\mathrm{p}=0.111)$, surgical intervention performed to remove the tumour $(\mathrm{P}=0.203)$, external ventricular drain insertion $(\mathrm{p}=0.196)$, multiple hospital admissions $(\mathrm{p}=0.069)$, number of surgeries $(\mathrm{p}=0.148)$, tumour histology $(\mathrm{P}=0.221)$, tumour recurrence $(\mathrm{p}=0.076)$,
Table 2 Summary of final reduced multivariate models using Cox algorithm to predict prevalence of depressive symptoms and its association with functional status

\begin{tabular}{lll}
\hline Variable & PR and $95 \% \mathbf{C l}$ & P value \\
\hline KPS scores $>70 *$ & 1 & - \\
KPS scores $\leq 70$ & $3.25(1.87-5.62)$ & $<0.001$ \\
\hline
\end{tabular}

${ }^{*}$ Reference category which was kept as reference in analysis. KPS, Karnofsky Performance Scores; PR, prevalence ratio.

tumour involving seller region (brain structure involved) $(\mathrm{p}=0.106)$ and tumour involving cerebellum/cerebellopontine angle $(p=0.046)$ had $p$ value of $\leq 0.25$. After adjusting for the effect of other variables in the multivariable model, functional status (KPS) remained the only variable found associated with depressive symptoms among patients with primary brain tumour with $\mathrm{p}<0.001$.

Table 2 shows that the prevalence of depression among patients with KPS scores $\leq 70$ is 3.25 times more as compared with patients with KPS scores $>70$.

Propensity scores for functional status showed three factors that were significantly associated with functional status including employment status, tumour recurrence and treatment stage at the time of the interview. Table 3 shows factors associated with functional status (KPS).

Propensity scores predicted from the above model were significantly associated with depression. Table 3 shows models to demonstrate the association of propensity scores for functional status (KPS) with depression after controlling for current employment status, treatment stage and tumour recurrence.

Table 4 shows that with each unit increase in propensity scores for functional status, the depression will increase up to $5 \%$.

\section{DISCUSSION}

The purpose of the present study was to investigate the association between depression and patient-related, tumor-related and treatment-related variables among adult patients with primary brain tumours. Although similar studies have been conducted in different parts of the world, most notably in the US and UK, there is no literature from LMICs or even other South Asian countries. We believe that the circumstances for our patients differ from those of the west, for a number of reasons. According to WHO, Pakistan has one of the world's lowest public health expenditure as a percentage of gross domestic product, as well as one of the world's highest out-of-pocket health expenditure, where it shares the top slot with other South Asian LMICs. Thus approximately $85 \%$ of our patients are out-of-pocket payers, in a country already marred with poverty, compared with the high-income countries where the majority of patients are financially supported by third party payers, that is, state or insurance. ${ }^{13}$ In this setting, the high cost of treatment for brain tumours (surgery, chemotherapy, radiation 


\begin{tabular}{|c|c|c|c|c|}
\hline S\# & Variables & PR and $95 \% \mathrm{Cl}$ & $P$ value $(z)$ & $P$ value $(F)$ \\
\hline \multirow[t]{4}{*}{1} & Current employment status & & & \\
\hline & Able to work * & 1 & - & \\
\hline & Unable to work & $2.56(0.95-6.92)$ & 0.063 & \\
\hline & Unpaid (student/retired/housewives) & $2.66(1.07-6.66)$ & 0.034 & \\
\hline \multirow[t]{5}{*}{2} & Treatment stage & & & \\
\hline & Underwent surgery only & $7.17(2.88-17.89)$ & $<0.001$ & $<0.001$ \\
\hline & Referral given to oncology after surgery & $1.91(0.55-6.64)$ & 0.306 & \\
\hline & Oncology treatment started/continued & $1.86(0.59-5.79)$ & 0.282 & \\
\hline & Treatment completed/follow-ups * & 1 & - & \\
\hline \multirow[t]{3}{*}{3} & Tumour recurrence & & & \\
\hline & Yes & $1.97(0.89-4.35)$ & 0.09 & \\
\hline & $\mathrm{No}^{*}$ & 1 & - & \\
\hline
\end{tabular}

${ }^{*}$ Reference category which was kept as reference in analysis.

KPS, Karnofsky Performance Scores; PR, prevalence ratio.

therapy, rehabilitation and so on) should theoretically add to the psychological stress of the patients. Although government-run hospitals do exist, they cover only a fraction of the overall healthcare, and the majority of patients have to resort to private hospitals, especially for advanced healthcare. There are also very few state-run oncology or rehabilitation centres, and patients have to rely on private healthcare for all these services.

We found that $39 \%$ of patients with a primary brain tumour treated at AKUH, screened positive for depression on PHQ-9. Impaired functional status was the only significant variable associated with depression and propensity scores for functional status revealed a significant association between impaired functional status and treatment stage at the time of the interview, unemployment and tumour recurrence. We also found that decreasing KPS was directly linked to increased chances of depression; as in with each unit increase in propensity scores for functional status, chances of depression increased by up to $5 \%$. Our findings are consistent with some of the previous studies on the same topic. Rooney et $a l^{12}$ in their systematic review of observational studies concluded that the median prevalence of depression among patients with brain tumour using screening scales was about 27\% (range 0\%-93\%), while clinicianrated measures returned up to $15 \%(5 \%-28 \%)$. Another meta-analysis conducted by Huang et $a l^{21}$ reported that

Table 4 Summary of association between propensity scores for functional status (KPS) with depressive symptoms after adjusting for current employment status, treatment stage and tumour recurrence

\begin{tabular}{lll}
\hline Variable & PR and 95\% CI & P value \\
\hline Propensity scores for KPS & $1.05(1.02-1.08)$ & $<0.001$ \\
\hline
\end{tabular}

KPS, Karnofsky Performance Scores; PR, prevalence ratio. the prevalence of depression in patients with brain tumour is nearly $21 \%$ using screening scales and $19 \%$ with clinician-rated measures, specifically including mini-interviews. A 1-year follow-up study conducted by Mainio $e t a l^{22}$ also found functional status as a significant predictor associated with depression among patients with brain tumour. Similar findings were observed in observational studies conducted by Anderson et al, ${ }^{23}$ Litofsky $e t a l,^{24}$ Grant $e t a l,{ }^{25}$ Fox $e t a l,{ }^{26}$ Rooney $e t a l^{27}$ and Piil et al. ${ }^{28} 29$

We found three factors associated with reduced functional status including unemployment, tumour recurrence and stage of treatment, more specifically, the early stage of treatment. Association between employment status and depression has been explored by other investigators too. A study conducted by Pelletier $e$ t $a \hat{l}^{30}$ found employment status positively associated with depression among patients with brain tumours. However, this association was significant only at the univariate level. Another study conducted by van der Vossen $e t a l^{31}$ on cognitive and emotional problems among patients with meningioma reported a significant association between depression and employment status where depression was assessed by hospital anxiety and depression scale. However, when depression was assessed by other screening tools, no association was found. In contrast, employment status was found to be significantly associated with functional status. A follow-up study conducted by Hickmann $e t a l^{2}$ reported a parallel trend of unemployment as the functional status declines. Though none of the studies have reported any definite association between unemployment and reduced functional status among similar populations, trends and figures explained by previous studies, as well as common sense, support this relationship, especially in countries without unemployment benefits or without adequate labour laws safeguarding employee rights during illnesses. 
We did not find any significant association between tumour recurrence and depression and similar findings were reported by van der Vossen et al. ${ }^{31}$ On the other hand, reduced functional status was significantly associated with tumour recurrence, as shown by other investigators as well. ${ }^{334}$ We included patients with brain tumour during different treatment stages after surgical procedure was done. Patients immediately after surgery and in their initial stage of treatment reported the highest prevalence of depression (82\%). Weitzner, ${ }^{35}$ Pringle $e t a l^{36}$ and Mainio $e t a t^{2}$ also reported a higher level of depression during the initial stage of treatment that is within the first 3 months after surgery. This variable was also found significantly associated with an impaired functional status that is understandable given the physiological and psychological effects of major surgery and hospitalisation. As the treatment progresses and by the time it comes to its end, patients tend to regain their functional status and even resume their jobs. Most patients with brain tumour who have transient focal deficits because of surgery, by the time they reach the completion of their treatment, also improve in their overall functional status. However, no statistical evidence has been reported by any study on the association between functional status and treatment stage.

This study had few limitations. First, we conducted a cross-sectional study which by default does not conclude any temporal relationship between explanatory variables and the outcome. Though our study provides new insight into the psychological burden patients with brain tumour may experience along with its associated factors, the results of this study must be interpreted with caution. However, future studies with larger sample size and different prospective designs are required to hypothesise any specific association. Second, we used a single screening tool to measure depression. We did not use physician-rated measures or mini-interviews to verify the results of PHQ-9. This might have overestimated the prevalence of depression among study participants. However, our study aimed to screen patients for depressive symptoms and not to diagnose, thus, only one screening tool was used. Moreover, to prevent excessive fatigue to the patients, we decided to take less time off our participants. Therefore, a screening tool was considered best to screen for depressive symptoms instead of interviews which could have taken a long time. Third, this study was a singlecentre study and thus results cannot be generalised to the entire population of patients with brain tumour. Though we included a diversified group of patients with different ethnic and cultural backgrounds, there is a possibility that patients who presented to government and semigovernment sectors for the treatment of brain tumours might have different socioeconomic backgrounds and other demographic characteristics. There is a possibility that patients presented to other care settings apart from AKUH might have different predisposing factors that lead to depression. Therefore, we cannot generalise our results to all patients with brain tumour. However, our findings do represent a group of patients with brain tumour presented to private tertiary care settings in Pakistan.

\section{CONCLUSION}

Our findings suggest that a high proportion of patients with brain tumour also suffer from depression. Whereas several individual and clinical factors may contribute to the development of depression, patients with reduced functional status should be specially monitored for any signs of psychiatric illness. Given the high proportion of depressed patients in our study population, we would recommend routine psychiatric evaluation, or at the least, the administration of simple self-rated screening tools that will allow healthcare providers to readily identify any prevailing neuropsychiatric ailments, for all patients with brain tumours, at the time of admission and during follow-ups.

Acknowledgements The authors would like to acknowledge Aga Khan University Hospital, all the nursing and paramedical staff, and all the residents and consultants who assisted in this project.

Contributors ASP-study design, formulation of questionnaire, data collection, data analysis, manuscript writing. ARS—study design, epidemiological expertise in design and implementation phase, manuscript writing and review. IAbiostatistician (analysis of study data), manuscript writing and review of study analysis. MSS-design and implementation of study, neurosurgery expert input in the design and analysis phase, manuscript review and writing. AAJ—design and implementation of study, oncology expert input in the design and analysis phase, manuscript reviewing. SK—design and implementation of study, selection of study tools, psychology expert input in the design and analysis phase, manuscript reviewing.

Funding This was a self-funded study

Competing interests None declared.

Patient consent for publication Not required.

Ethics approval Aga Khan University Institution Review Board (5009-CHS-ERC-17).

Provenance and peer review Not commissioned; externally peer reviewed.

Data availability statement Data are available upon reasonable request. The data that support the findings of this study are available from the corresponding author upon reasonable request.

Open access This is an open access article distributed in accordance with the Creative Commons Attribution Non Commercial (CC BY-NC 4.0) license, which permits others to distribute, remix, adapt, build upon this work non-commercially, and license their derivative works on different terms, provided the original work is properly cited, appropriate credit is given, any changes made indicated, and the use is non-commercial. See: http://creativecommons.org/licenses/by-nc/4.0/.

ORCID iD

Anum Sadruddin Pidani http://orcid.org/0000-0003-1879-9917

\section{REFERENCES}

1 Rooney AG, Brown PD, Reijneveld JC, et al. Depression in glioma: a primer for clinicians and researchers. J Neurol Neurosurg Psychiatry 2014;85:230-5.

2 Madhusoodanan S, Ting MB, Farah T, et al. Psychiatric aspects of brain tumors: a review. World J Psychiatry 2015;5:273.

3 Goebel S, Stark AM, Kaup L, et al. Distress in patients with newly diagnosed brain tumours. Psychooncology 2011;20:623-30.

4 Bunevicius A, Deltuva V, Tamasauskas S, et al. Screening for psychological distress in neurosurgical brain tumor patients using the patient health Questionnaire-2. Psychooncology 2013;22:1895-900. 
5 Watson D. Rethinking the mood and anxiety disorders: a quantitative hierarchical model for DSM-V. J Abnorm Psychol 2005;114:522-36.

6 Tucci V, Moukaddam N. We are the hollow men: the worldwide epidemic of mental illness, psychiatric and behavioral emergencies, and its impact on patients and providers. J Emerg Trauma Shock 2017;10:4.

7 Ferrari AJ, Somerville AJ, Baxter AJ, et al. Global variation in the prevalence and incidence of major depressive disorder: a systematic review of the epidemiological literature. Psychol Med 2013;43:471-81.

8 Massie MJ. Prevalence of depression in patients with cancer. J Natl Cancer Inst Monogr 2004;2004:57-71.

9 Ahsan J, Hashmi SN, Muhammad I, et al. Spectrum of central nervous system tumours--a single center histopathological review of 761 cases over 5 years. J Ayub Med Coll Abbottabad 2015;27:81-4.

10 Rooney AG, Carson A, Grant R. Depression in cerebral glioma patients: a systematic review of observational studies. J Natl Cancer Inst 2011;103:61-76.

11 Petruzzi A, Finocchiaro CY, Lamperti E, et al. Living with a brain tumor. Supportive Care in Cancer 2013;21:1105-11.

12 Rooney AG, Carson A, Grant R, et al. Depression in cerebral glioma patients: a systematic review of observational studies. J Natl Cancer Inst 2011;103:61-76.

13 Rahman MM, Karan A, Rahman MS, et al. Progress toward universal health coverage: a comparative analysis in 5 South Asian countries. JAMA Intern Med 2017;177:1297-305.

14 Phellas CN, Bloch A, Seale C. Structured methods: interviews, questionnaires and observation. Researching society and culture 2011;3:181-205.

15 Gholizadeh L, Ali Khan S, Vahedi F, et al. Sensitivity and specificity of Urdu version of the PHQ-9 to screen depression in patients with coronary artery disease. Contemp Nurse 2017;53:75-81.

16 Arnold SD, Forman LM, Brigidi BD, et al. Evaluation and characterization of generalized anxiety and depression in patients with primary brain tumors. Neuro Oncol 2008;10:171-81.

17 Dean AG, Sullivan KM, Soe MM. OpenEpi: open source epidemiologic statistics for public health, version. Available: www. OpenEpi.com [Accessed 09 Mar 2019].

18 StataCorp. Stata statistical software: release 14. College Station, TX: StataCorp LP, 2015.

19 Barros AJD, Hirakata VN. Alternatives for logistic regression in crosssectional studies: an empirical comparison of models that directly estimate the prevalence ratio. BMC Med Res Methodol 2003;3:21.

20 Hosmer Jr DW, Lemeshow S, Sturdivant R. X. Applied logistic regression. 398. John Wiley \& Sons, 2013.
21 Huang J, Zeng C, Xiao J, et al. Association between depression and brain tumor: a systematic review and meta-analysis. Oncotarget 2017;8:94932-43.

22 Mainio A, Hakko H, Timonen M, et al. Depression in relation to survival among neurosurgical patients with a primary brain tumor: a 5-year follow-up study. Neurosurgery 2005;56:1234-42.

23 Anderson SI, Taylor R, Whittle IR. Mood disorders in patients after treatment for primary intracranial tumours. Br J Neurosurg 1999;13:480-5.

24 Litofsky NS, Farace E, Anderson F, et al. Depression in patients with high-grade glioma: results of the glioma outcomes project. Neurosurgery 2004;54:358-66.

25 Grant R, Slattery J, Gregor A, et al. Recording neurological impairment in clinical trials of glioma. J Neurooncol 1994;19:37-49.

26 Fox SW, Lyon D, Farace E. Symptom clusters in patients with highgrade glioma. J Nurs Scholarsh 2007;39:61-7.

27 Rooney AG, McNamara S, Mackinnon M, et al. The frequency, longitudinal course, clinical associations, and causes of emotional distress during primary treatment of cerebral glioma. Neuro Oncol 2013;15:635-43.

28 Piil K, Jakobsen J, Christensen KB, et al. Health-Related quality of life in patients with high-grade gliomas: a quantitative longitudinal study. J Neurooncol 2015;124:185-95.

29 Salander P, Bergenheim T, Henriksson R. The creation of protection and hope in patients with malignant brain tumours. Soc Sci Med 1996;42:985-96.

30 Pelletier G, Verhoef MJ, Khatri N, et al. Quality of life in brain tumor patients: the relative contributions of depression, fatigue, emotional distress, and existential issues. J Neurooncol 2002;57:41-9.

31 van der Vossen S, Schepers VPM, Berkelbach van der Sprenkel JW, et al. Cognitive and emotional problems in patients after cerebral meningioma surgery. J Rehabil Med 2014;46:430-7.

32 Hickmann A-K, Nadji-Ohl M, Haug M, et al. Suicidal ideation, depression, and health-related quality of life in patients with benign and malignant brain tumors: a prospective observational study in 83 patients. Acta Neurochir 2016;158:1669-82.

33 Bower JE. Cancer-related fatigue--mechanisms, risk factors, and treatments. Nat Rev Clin Oncol 2014;11:597-609.

34 Armstrong TS, Ying Y, Wu J, et al. The relationship between corticosteroids and symptoms in patients with primary brain tumors: utility of the dexamethasone symptom Questionnaire-Chronic. Neuro Oncol 2015;17:1114-20.

35 Weitzner MA. Psychosocial and neuropsychiatric aspects of patients with primary brain tumors. Cancer Invest 1999;17:285-91.

36 Pringle AM, Taylor R, Whittle IR. Anxiety and depression in patients with an intracranial neoplasm before and after tumour surgery. $\mathrm{Br} \mathrm{J}$ Neurosurg 1999;13:46-51. 